\title{
Liquid hydrogen fuel tanks for commercial aviation: Structural sizing and stress analysis
}

\author{
Arturo Gomez ${ }^{\mathrm{a}}$ and Howard Smith ${ }^{\mathrm{b}}$ \\ ${ }^{a},{ }^{b}$ Cranfield University, Bedfordshire, United Kingdom, MK43 OAL
}

\begin{abstract}
LH2 fuel tanks are one of the main drivers in the development of a commercial airplane powered with hydrogen. This article discusses the implementation of liquid hydrogen fuel tanks in future commercial airplanes focusing on the sizing of the fuel tank structure and its behavior under critical loading conditions. Fuel tanks are sized according to the mission requirements and geometrical restrictions of a conventional mid-range commercial airplane. Critical loading cases for symmetrical maneuvers and landing conditions are estimated following EASA CS25 airworthiness specifications for large airplanes. The stress distribution in each tank is evaluated using linear Finite Element Analysis (FEA) in MSC. NASTRAN/PATRAN to ensure that the structural design complies with strength and stiffness requirements
\end{abstract}

Keywords: Liquid hydrogen fuel tank, finite element analysis, aircraft loading, structural sizing.

${ }^{*}$ Corresponding author.

E-mail address: ing.arturoaero@hotmail.com 


\section{Nomenclature}

AFT afterward
A
area
$\left[\mathrm{m}^{2}\right]$
a
semi-minor axis
[m]
b
semi-major axis
[m]

CD airplanes' drag coefficient

CL airplanes' lift coefficient

DOF degree of freedom

E young's modulus

$[\mathrm{MPa}]$

$\mathrm{F}_{\text {ty }}$

material's tensile yield strength

[MPa]

FWD forward

$\mathrm{GH}_{2} \quad$ hydrogen gas

$h_{\lg } \quad$ enthalpy of vaporization

$[\mathrm{J} / \mathrm{Kg}]$

g

gravity acceleration

$\left[\mathrm{m} / \mathrm{s}^{2}\right]$

$\mathrm{k}$

Thermal conductivity

$[\mathrm{W} / \mathrm{m} . \mathrm{K}]$

KIC materials' toughness

[MPa]

ISA International Standard Atmosphere

$\mathrm{L}$

characteristic length

[m]

$\mathrm{LH}_{2} \quad$ liquid hydrogen

M.S. margin of safety

MTOW

maximum take-off weight

$[\mathrm{Kg}]$

$\dot{m}$

mass flow

$[\mathrm{Kg} / \mathrm{s}]$

$\mathrm{n}$

load factor

[g]

OEW

operational empty weight

$[\mathrm{Kg}]$

$\mathrm{P}$

pressure

[Pa] 


\begin{tabular}{|c|c|c|}
\hline Q & heat flux input & {$[\mathrm{W}]$} \\
\hline $\mathrm{R}$ & range & {$[\mathrm{Km}]$} \\
\hline $\mathrm{R}_{\mathrm{cyl}}, \mathrm{R}_{\mathrm{sph}}$ & \multicolumn{2}{|c|}{ Cylinder, Sphere thermal resistance (conduction) } \\
\hline$r_{o}, r_{i}$ & Outer, Inner tank radius & {$[\mathrm{m}]$} \\
\hline SFC & thrust specific fuel consumption & {$\left[\mathrm{hr}^{-1}\right]$} \\
\hline $\mathrm{T}$ & temperature & {$[\mathrm{C}]$} \\
\hline $\mathrm{V}$ & velocity & {$[\mathrm{m} / \mathrm{s}]$} \\
\hline $\mathrm{V}$ & tank volume & {$\left[\mathrm{m}^{3}\right]$} \\
\hline $\mathrm{W}_{0}$ & initial weight & {$[\mathrm{Kg}]$} \\
\hline $\mathrm{W}_{1}$ & zero fuel weight & {$[\mathrm{Kg}]$} \\
\hline $\mathrm{x}$ & fuel quality & \\
\hline$\rho$ & density & {$\left[\mathrm{Kg} / \mathrm{m}^{3}\right]$} \\
\hline$\sigma$ & normal stress & {$[\mathrm{MPa}]$} \\
\hline$\tau$ & shear stress & {$[\mathrm{MPa}]$} \\
\hline$\varphi$ & energy derivative & {$\left[\mathrm{Pa} /\left(\mathrm{J} / \mathrm{m}^{3}\right)\right]$} \\
\hline
\end{tabular}

\section{Introduction}

PETROLEUM based fuels have shown to be successful for airplane operations due to their high energy density, easy storability and safe handling. Other industries also benefit from similar fuels fostering the creation of an extensive supply infrastructure that allows them to be offered at relatively low prices. Challenges associated with climate change and current political tension in oil producer countries have created the necessity among airplane manufacturers to look for alternative fuels

\subsection{Green-house gases emissions}


Aviation is responsible for $3 \%$ of the total emission of $\mathrm{CO} 2$ in the atmosphere. The altitude where various products are emitted triggers the formation of condensation trails and an increase in cirrus cloudiness; two factors that contribute to climate change [1]. Air traffic is expected to grow during the next 20 years at rate of $4.5 \%$ per year [2] demanding 33.070 new airplanes. Advances in aerospace technology during the last 15 years have reduced the $\mathrm{CO} 2$ emissions by $34 \%$ (Kg of fuel per passenger per trip) being a reduction of $2.3 \%$ per year [2]. Despite these improvements, ICAO estimates that by 2050 aviation emissions are projected to be 3 to 7 times higher than in 2005. This reflects that technological improvements, during the last years, in operations, airframe design, and engine performance are not enough to compensate the emissions growth. For this reason, more radical alternatives are required to reach at least a $\mathrm{CO} 2$ neutral growth.

\subsection{Oil dependency}

Airplanes are dependent on oil-based fuels in such a way that the aviation sector accounts for around $6 \%$ of the total worldwide oil demand. [3]. Oil prices considerably affect the operational costs of commercial aviation being a critical variable from the business perspective. Statistics shows that $78.1 \%$ of the worldwide oil reserves belong to countries where there has been active geopolitical tension during recent years (e.g. Venezuela, Iraq, Iran, Kuwait, Lybia, Iran, Nigeria) [4]. Geopolitical tension in major oil producer countries generate important oil supply disruptions that can reach levels up to 5.6 million barrels per day [5]. These disruptions could increase the oil price dramatically. As example, the 1973 oil embargo by OAPEC increased the price of the barrel from US\$3 up to US\$12.

For the expressed reasons countries such as the United States, Russia, the European Union have tasked major airplane manufacturers to look for alternative fuels for aviation. 


\subsection{Hydrogen as an alternative fuel for aviation}

Hydrogen is the most abundant substance in the universe however; it is not found on Earth in a pure state and therefore is produced artificially. In this sense hydrogen can be considered as an energy storage mechanism rather than a proper fuel. If stored in its liquid state liquid hydrogen (LH2) provides many advantages over kerosene-based fuels; among them [6]:

a. Local production: Hydrogen can be produced through electrolysis of water in any region with access to water and an electrical supply.

b. Minimal greenhouse gas emissions: If produced through alternative energy sources (hydroelectric, solar, wind, geothermal) hydrogen is relatively free from greenhouse emissions. Additionally the combustion product of Hydrogen and Oxygen is water vapor, that if emitted in the upper atmosphere will remain for as long as one year compared to the 200 years that $\mathrm{CO} 2$ remains in the atmosphere [7]

c. High energy density: Hydrogen's combustion heat per unit of weight is around 2.8 times higher than kerosene. This allows commercial airplanes to increase their range or payload without increasing the fuel weight [8]

d. Cooling capability: Due to the cryogenic temperatures in which liquid hydrogen has to be stored this fuel can be used as a more efficient cooling fluid for the engine and electrical parts.

\subsection{LH2 storage in commercial airplanes}

At ambient conditions, hydrogen is an overheated gas with a very high specific volume, higher than kerosene based fuels. Making hydrogen a fuel for aerospace vehicles requires it to be stored in a liquid state (LH2) at cryogenic temperatures and high pressures.

Some of the challenges of implementing LH2 fuel tanks in aviation are: 
a. Available space: LH2 requires around 4 times more storage volume than kerosene requiring modifications to the airplane layout that affects its aerodynamic efficiency and reduces the available space for payload.

b. Insulation is required to minimize heat transfer into the tank and maintaining the internal pressure and temperature at moderate levels. Over pressure in the tanks due to boil off generates the need to release the excess pressure causing a decrease in the overall airplane performance [8]

c. Explosions and the fire hazard due to the violent exothermic reactions resulting from ignition with oxygen or abrupt depressurization of the tank due to structural failure could result in catastrophic incidents.

d. Fatigue life: Fueling cycles are potential sources of fatigue failure in a LH2 fuel tank. Embrittlement due to low temperatures increases the yield strength of the material and its endurance limit. However, the associated decrease in ductility reduces the toughness of the material and therefore the number of cycles to failure. [9]. Additionally, continuous contact with hydrogen gas generate hydrogen-embrittlement that can accelerate the initiation of surface flaws. [9]

e. Empty weight: Increase in the airplane OEW due to structural reinforcement, insulation and maintenance facilities required in a LH2 fuel tank.

f. C.G. location: Modern commercial airplanes carry most of their fuel in integral tanks located in each airplane wing. This configuration avoids large changes in the C.G. location as the fuel is consumed. Diverse studies [8], [10], [11] have shown that such a configuration is unviable for LH2 commercial airplanes due to the extensive volume required. For such a reason the LH2 has to be distributed along the airplane's longitudinal axis - a very sensitive location for the airplane's longitudinal stability. 
For the reasons stated above, the design of the LH2 fuel tanks is one of the main drivers in the development of a LH2 commercial airplane

\section{Storage of hydrogen in aerospace vehicles}

Early in the $20^{\text {th }}$ century, large airships, such as the British R101 and the German LZ 129 Hindenburg, used hydrogen gas (GH2) to sustain flight. GH2 was contained in a duralumin and stainless steel airframe covered by a doped cotton that prevented damage from solar radiation. Gasbags made from layers of latex were used to contain the GH2.

The first attempt of using hydrogen as an aviation fuel took place in 1955 when the U.S. Air Force, NACA, and Silverstein Hall modified a B-57 bomber to fly with liquid hydrogen. Two LH2 fuel tanks made from stainless steel and pressurized to 3.4 atmospheres were located in the wing tips. It used $5 \mathrm{~cm}$ of foam insulation covered by aluminum. [12]. Years later, in 1962, the Atlas-Centaur rocket became the first rocket to be powered by hydrogen. It was designed in such a way that compressive loads and bending moments were stabilized by the internal pressure of the LH2 tank. Although its first flight resulted in failure due to the damage of the insulation, after some redesigns the Atlas-Centaur was the first rocket to land the Surveyor probe on the moon. [13]

Under the oil crisis of 1970s the U.S. government tasked NASA, Lockheed Martin and others to develop the first comprehensive study about the challenges of designing LH2 commercial airplanes. This study was based on a 400 passenger airliner with 5500 miles of range. The airplane design consisted of two LH2 fuel tanks made from Al-2219 located forward and aft in the fuselage. These tanks operate at a maximum pressure of $21 \mathrm{psi}$ and a minimum temperature of $-251.4^{\circ}$ C. Some conclusions of this study with regard to the structural design of LH2 fuel tanks for aviation are [8]:

- Tank pressure should be higher than atmospheric to prevent air ingestion that may cause an explosion hazard 
- Non-integral fuselage tanks require a larger available volume to store LH2

- Due to maintenance difficulties, LH2 fuel tanks should be designed for a full service life

- Fuel weight fraction $\left(\mathrm{W}_{\mathrm{T}} / \mathrm{W}_{\mathrm{LH} 2}\right)$ of a $\mathrm{LH} 2$ integral tank is 0.196

- $\quad$ Elliptical domes with $(\mathrm{a} / \mathrm{b}=1.66)$ offer the best combination of weight and tank length

With the space shuttle, $\mathrm{LH} 2$ took its place as the main propellant of rocket engines. Its external tank contained LH2 at 32 to 34 psi in the aft section using a semi-monocoque structure made from Al-2195 and 2029. It had elliptical domes produced in Al-2219 due to welding easiness. The forward dome, ahead of the oxygen, incorporated vent valves and pressurization fittings.

In 1988 the Tupolev modified one engine of a Tu-154 aircraft to run hydrogen as fuel. A cryogenic fuel tank was implemented in the rear fuselage using a pressure bulkhead. This pressure bulkhead enabled the maintenance of a higher pressure in the rear part isolating the crew members from any fire hazard.

Between 1998 and 2002 the European Union commissioned Airbus and an extensive group of manufacturers and universities (e.g. Cranfield, TU Delft, Hamburg, TU Munich) to study possible airplane configurations that might allow a smooth transition from kerosene to hydrogen. The project, called Cryoplane, gave the following conclusions with regard to the fuel tank design:

- For small regional airplanes a single LH2 tank can be located behind the pressure bulkhead, meanwhile, for middle and long-range airplanes a forward location of LH2 tank is required to maintain the C.G. within the allowable range

- $\mathrm{OEW}$ increases by $23 \%$ due to the implementations of the additional LH2 tank structure 
During recent years NASA and Boeing have worked in the development of the Space Launch System (SLS), an LH2 rocket that has the ultimate goal of taking humans to Mars. Its fuel tank is composed of five separated barrels made from Al-2219 integrally machined in an orthogrid pattern. They are welded using friction stir welding to achieve strong bonds almost free from defects.

Alternative technologies are developed by NASA under the "game-changing" project in which LH2 fuel tanksare made by 'out of autoclave' composite materials Cytec's CYCOM 53201/IM7 pre-preg using automated fibre placement. This allowed the use of thin plies that avoided the micro cracking that causes leaks; according to NASA this technique has eliminated completely the permeability to hydrogen. Additionally, it could achieve a $30 \%$ weight reduction and $25 \%$ cost savings if compared to current metallic tanks.

One of the latest applications of LH2 as aviation fuel is the Phantom Eye; a high altitude and high endurance unmanned aerial vehicle developed by Boeing in 2008 [14]. Phantom Eye has two spherical tanks $8 \mathrm{ft}$ in diameter that stores LH2 at $95 \mathrm{psig}$. The fuel tanks are made from hemispherical heads in aluminum welded in the center and stiffened with ribs $1.4 \mathrm{~m}$ tall.

\section{The design platform}

Providing a realistic scenario to size and perform stress analysis over LH2 fuel tanks requires the modification of an existing airplane design with a conventional airliner configuration. The chosen design is the MRT7-3 "Meridian" (Smith, 2007), a conventional midrange civil transport designed in 2008 at Cranfield University. The implementation of LH2 fuel tanks in this design should be such that changes in the airframe, aerodynamic shape and mass distribution are maintained to a minimum. Figure 1 shows the main modifications in the cabin layout. Two LH2 fuel tanks are located in the forward and aft sections of the fuselage. This configuration is the most efficient in terms of available space, C.G. relocation, and structural 
stiffness to resist pressure hoop stresses [8], [10]. This airframe is redesigned following EASA CS-25 airworthiness specifications, and ANSI/AIAA S-080 standards for pressurized structures [15] [16] .
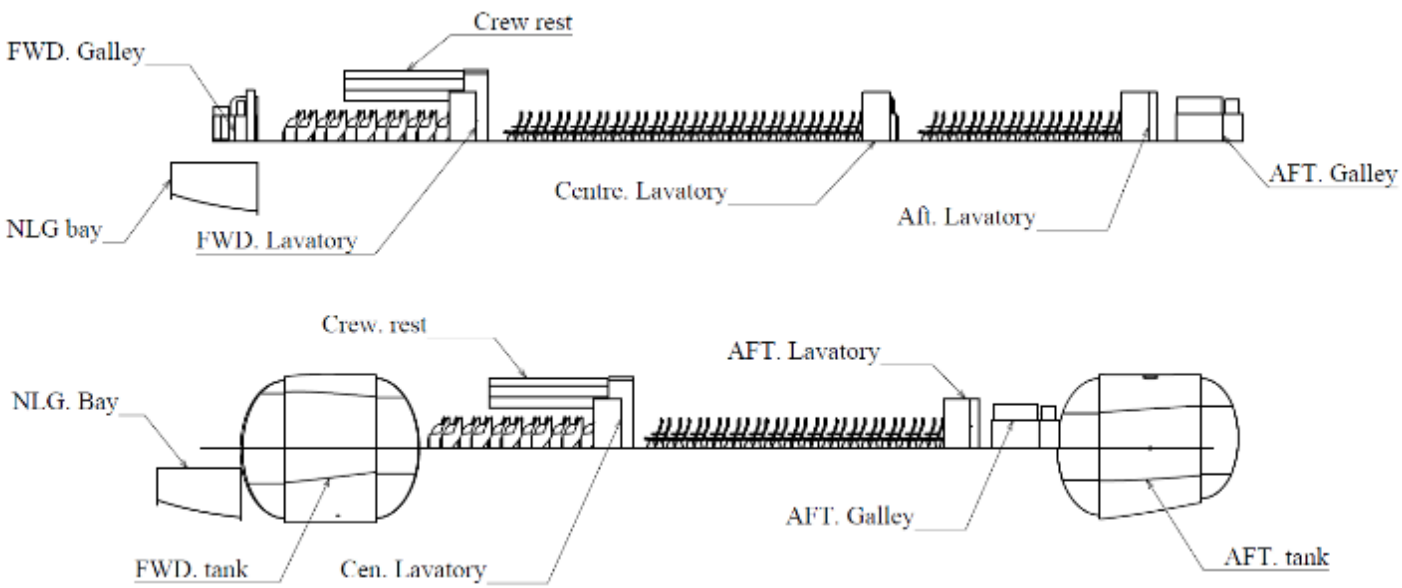

Figure 1. Changes in cabin layout

\subsection{Fuel tank sizing and cabin layout}

The amount of LH2 to be stored inside the fuel tanks is estimated using the Breget's equation for a range of $9.000 \mathrm{Km}$. The specific fuel consumption (SFC) is assumed to be $0.22 \mathrm{hr}^{-1}$; a conservative value considering previous studies about LH2 turbofan engines [8], [10], [17].

$$
R=\frac{2}{S F C} \sqrt{\frac{2}{\rho S}} \frac{C_{L}^{\frac{1}{2}}}{C_{D}}\left(W_{0}^{\frac{1}{2}}-W_{1}^{\frac{1}{2}}\right)
$$

Some passenger seats are removed from the initial cabin configuration in order to have enough space to locate the LH2 fuel tanks Figure 1. Due to the compromise between aerodynamic, performance and geometrical variables the exact amount of fuel required and the total number of passengers removed are estimated using a numerical iteration. The summary of this calculation is shown in Table $\mathbf{1}$

\begin{tabular}{lll}
\hline & MRT7-3 & MRT7-3 (LH2) \\
\hline Range (Km) & 6500 & 9000 \\
Fuselage length (m) & 56 & 56
\end{tabular}




$\begin{array}{lll}\text { Passengers (Two conf.) } & 296 & 197 \\ \text { Mass (Kg) } & & \\ \text { MTOW } & 186177 & 133676 \\ \text { OEW } & 103916 & 108897 \\ \text { Fuel mass (Kg) } & 37475 & 17700 \\ \text { C.G. location (m) } & & \\ \text { MTOW } & 24.94 & 25.60 \\ \text { OEW } & 25.49 & 25.62\end{array}$

\section{Table 1. Comparison MRT7-3 and MRT7-3 (LH2)}

From Figure 1 it can be seen that the first tank is located in the forward fuselage between the Nose landing gear bay and the business class passenger cabin. In this area a narrow catwalk between the tanks and the fuselage gives the crew free access into the passengers cabin. The second fuel tank is located in the aft section of the fuselage between the aft galley and the APU. To maintain the C.G. in the allowable range the FWD galley and the center lavatory is removed as well as 13 passenger's seat rows. Additionally, the whole of the remaining passenger cabin is relocated $6.4 \mathrm{~m}$ rearwards.

\subsection{Tank insulation and storage conditions}

LH2 is stored at low temperatures as a saturated liquid/gas mixture. During the flight the tank is exposed to heat input from the surroundings producing fluctuations in the internal pressure and temperature; a $15 \mathrm{~mm}$ thick Inner Wetted Thermal Insulation (IWTI) is used to minimize heat transfer. The IWTI is an insulation foam based on polyurethane (PU) with metallic liners specifically developed for cryogenic LH2 conditions that can be applied internally as a sprayon foam [18]. The internal insulation system avoids the direct contact between LH2 and the tank structure maintaining it at almost ambient temperature and avoiding heat conduction along stringers, frames, and the external supporting rods. 


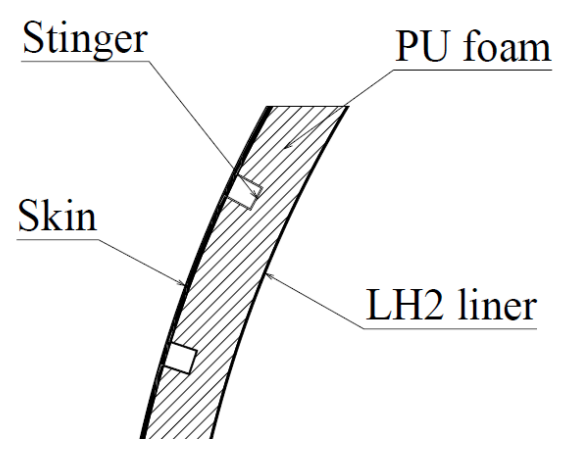

Figure 2. Internal thermal insulation

A venting valve is also located to avoid overpressure and maintain the structural integrity of the tank. The venting pressure is $\mathrm{P}=0.172 \mathrm{MPa}(25 \mathrm{psi})$ at $\mathrm{T}=-250.6 \mathrm{C}(22.5 \mathrm{~K})$ following similar storage conditions to [8] and [10]. This is a critical value since for low venting pressures, a significant amount of hydrogen needs to be vented or thick insulation is required whilst for high venting pressures thick tank walls are required. The maximum volume required is $297 \mathrm{~m} 3$ including a $5.2 \%$ of allowances due to tank contraction, internal equipment, boil-off, trapped and unusable fuel [8].

In order to evaluate the effectiveness of the proposed insulation, a typical cruise flight condition is analyzed and the pressure increment estimated. The complex coupling between the heat input, the storage conditions and the fuel level makes it necessary to have the following assumptions: constant flight altitude (35000ft or $10.66 \mathrm{Km})$, air properties at ISA conditions, flight speed Mach 0.85 , constant fuel level at $75 \% \mathrm{~W}_{\text {fuel }}$ at $\mathrm{P}=0.152 \mathrm{MPa}$. Additionally, as a design constraint, no venting fuel is considered during cruise flight.

The pressure variation is determined by applying the first law of thermodynamics and conservation of mass through the following equation [19]:

$$
\frac{d p}{d t}=\frac{\varphi}{V}\left(Q-\dot{m}_{\text {out }} h_{l g}\left[x \frac{\rho_{g}}{\rho_{l}-\rho_{g}}\right]\right)
$$


The heat input $\mathrm{Q}$ is estimated using a thermic resistance model similar to [20]. For external convection, the thermal resistance is calculated from the Nusselt number of a flat plate. Then the heat transfer coefficient for convection $\left(h_{\text {ext }}\right)$ is calculated as follows

$$
N u=\frac{h_{\text {ext }} L}{k_{\text {air }}}
$$

For external radiation, the heat transfer coefficient $\left(\mathrm{h}_{\mathrm{rad}}\right)$ can be found as follows

$$
h_{\text {rad }}=\sigma \varepsilon\left(T_{\text {skin }}^{2}+T_{\text {atm }}^{2}\right)\left(T_{\text {skin }}+T_{\text {atm }}\right)
$$

The combined thermal resistance for external convection and radiation is given by:

$$
R_{\text {ext }}=\frac{1}{2 \pi r_{o} L}\left(\frac{1}{h_{\text {ext }}+h_{\text {rad }}}\right)
$$

In the case of heat conduction through the insulation, the barrel section is assumed as a perfect cylinder whilst the domes are assumed as a semi-spherical shape. The catwalk is modelled as a flat surface in contact to steady air from the cabin. Due to the linear behaviour of the insulation's thermal conductivity a mean value is taken over the temperature range $\left(\mathrm{k}_{\text {foam }}=0.00675 \mathrm{~W} / \mathrm{m} . \mathrm{K}\right)$. The thermal resistances for conduction along the insulation in the barrel section, the domes, and the catwalk are given by:

$$
R_{b a r}=\frac{\ln \left(\frac{r_{o}}{r_{i}}\right)}{2 \pi L k}, \quad R_{d o m}=\frac{\mathrm{r}_{\mathrm{o}}-r_{i}}{4 \pi r_{o} r_{i} k}, \quad R_{c a t}=\frac{t}{k A}
$$

The total pressure increments during the flight segment are $20.3 \mathrm{KPa}$ and $18.4 \mathrm{KPa}$ for the FWD and AFT tank respectively. For both cases, the pressure is maintained at allowable levels to avoid venting fuel during cruise flight. Figure 3 shows the heat input contributions from the skin, domes and catwalk for both tanks. It can be noticed that the heat transfer along the FWD tank is $10.5 \%$ higher than the AFT tank due to the presence of the catwalk. This difference arises because the catwalk is in direct contact with the air of the cabin that is at a higher temperature for the passenger's comfort. Additionally, in the case of the AFT tank, the heat flux along the domes is comparable to the heat flux along the barrel section for the same reason. 


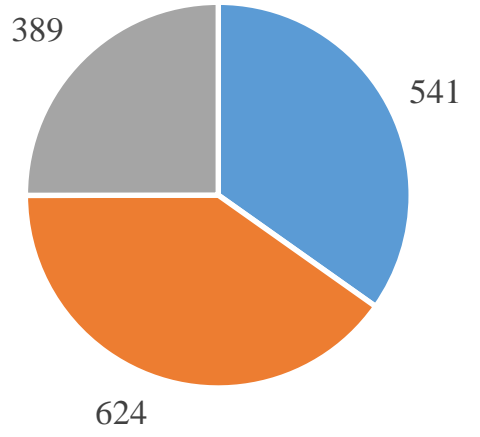

- Skin (Watts) $\quad$ Semi-domes (Watts)

- Catwalk (Watts)

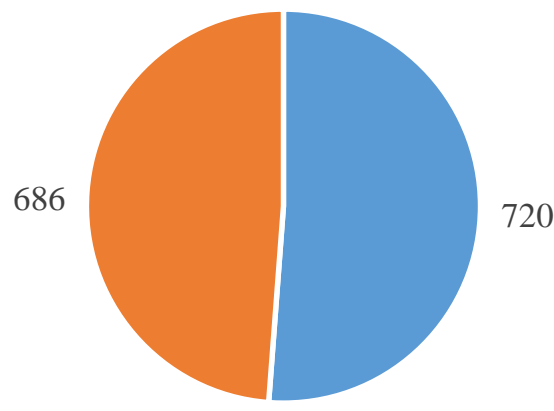

- Skin (Watts) - Domes (Watts)

Figure 3. Mean heat input for main structural components. a) FWD tank, b) AFT tank

Detailed thermal analyses are beyond the scope of this work. The reader is encouraged to refer to [20] and [21] for further information.

\section{Structure sizing}

\subsection{Description}

Both fuel tanks are designed as integral fuel tanks using the semi-monocoque fuselage structure to contain the fuel. Each tank is enclosed through semi-elliptical domes located at the ends of the tank. Both tank structures are stiffened with stringers and frames located at a constant pitch of $528 \mathrm{~mm}$ for the FWD tank and 513mm for the AFT tank. A summary of the structural sizing is presented in Table 2

\begin{tabular}{lll}
\hline Detail & FWD tank & AFT tank \\
\hline Length $(\mathrm{m})$ & 7.14 & 7.41 \\
Max. Height $(\mathrm{m})$ & 5.97 & 5.84 \\
Total weight $(\mathrm{Kg})$ & 3134 & 1847 \\
\hline \multicolumn{3}{l}{ BARREL SECTION } \\
Skin thickness $(\mathrm{mm})$ & 2 & 2 \\
Skin material & Al-2219-T87 & Al-2219-T87 \\
No. stringers & $44 \quad 44$ \\
No. fus. Frames & $8 \quad$ Al-7075-T6 & 9 \\
Material & \multicolumn{2}{c}{ DOMES } \\
& Elliptical $(\mathrm{a} / \mathrm{b}=1.6)$ & Elliptical $(\mathrm{a} / \mathrm{b}=1.6)$
\end{tabular}




\begin{tabular}{lll} 
No. stiffeners & 21x2 & 44×2 \\
Material & Al-7075-T6 & Al-7075-T6 \\
Skin thickness (mm) & 2.5 & 2 \\
Skin material & Al-2219-T87 & Al-2219-T87 \\
& CATWALK & \\
No. long. Stiffeners & 3 & N/A \\
Material & Al-7075-T6 & N/A \\
No. vert. stiffeners & 13 & N/A \\
Material & Ti-6Al-4V & N/A \\
Skin thickness (mm) & 5.5 & N/A \\
Material & Al-7075-T6 & N/A \\
\hline \multicolumn{2}{c}{ Table 2. Structural sizing LH2 fuel tanks }
\end{tabular}

\section{Table 2. Structural sizing LH2 fuel tanks}

From Figure 4 it can be seen that the FWD tank has a vertical wall, located on one side of the tank. This wall provides a boundary between the pressurized area and the catwalk. The catwalk wall is stiffened with vertical frames and longitudinal stringers. Additionally, 32 rods are used to transfer pressure loads from the catwalk wall into the fuselage airframe.
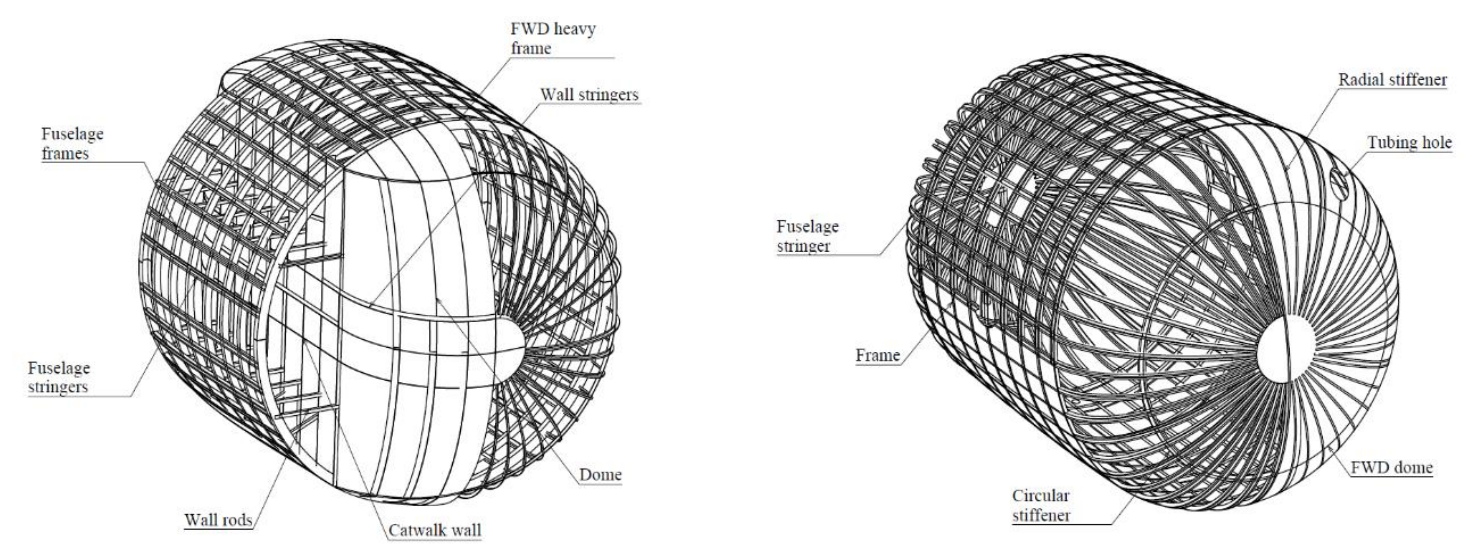

Figure 4. Fuel tanks structural arrangement

\subsection{Materials}

Aluminum 2219-T87 is used for the tank skin due to the good relationship between strength and fracture toughness. This alloy has been widely used in cryogenic aerospace applications due to its easy weld-ability. Aluminum 7075-T6 is a strong and lightweight alloy used in structural members such as stingers, and frames that are subjected to higher stress levels than 
the skin. Additionally, this alloy is also employed in the catwalk wall skin due to the higherpressure hoop stresses in this region.

Stiffeners, vertical frames and diagonal rots located in the catwalk are subjected to very high hoop stresses requiring the use of Ti-6Al-4V alloy. Table 3 shows the mechanical properties of all materials used in the structure of the fuel tanks. Yield strength is shown for cryogenic and normal temperatures.

\begin{tabular}{|c|c|c|c|c|c|c|}
\hline \multirow[b]{2}{*}{ Material } & \multirow[b]{2}{*}{$\rho(\mathrm{Kg} / \mathrm{m} 3)$} & \multicolumn{4}{|c|}{$\mathrm{T}=24 \mathrm{C}$} & \multirow{2}{*}{$\begin{array}{l}\mathrm{T}=-251 \mathrm{C} \\
\mathrm{F}_{\mathrm{ty}}(\mathrm{MPa})\end{array}$} \\
\hline & & $F_{t y}(\mathbf{M P a})$ & $\mathbf{E}(\mathbf{G P a})$ & $\begin{array}{l}\alpha \quad(\times 10-6 \\
\mathrm{mm} / \mathrm{mm} / \mathrm{C})\end{array}$ & $\begin{array}{ll}\mathrm{K}_{\mathrm{IC}} & (\mathrm{MPa} \\
\left.\mathrm{m}^{\wedge} \mathbf{1} / 2\right) & \end{array}$ & \\
\hline 2024-T3 & 2768 & 310.3 & 72.4 & N/A & 34 & 465.4 \\
\hline 2219-T87 & 2851 & 351.6 & 72.4 & 21.96 & 29.6 & 471.2 \\
\hline 7075-T6 & 2795.7 & 482.7 & 71 & 19.26 & 28.5 & 637.1 \\
\hline Ti-6AI-4V & 4428.8 & 951.5 & 116.5 & 9 & N/A & 1712.7 \\
\hline
\end{tabular}

\section{Table 3. Material properties}

\section{Loading cases}

Critical loading cases were estimated following the CS-25 airworthiness specifications for symmetric pull-up manoeuvres and landing conditions. For all cases most critical FWD and AFT C.G. locations where used.

\subsection{Mass distribution}

The mass distribution is an important parameter in the estimation of the inertial relief of the airplane at each loading condition. The mass distribution of the airplane was estimated based on the main modifications from the original airplane configuration. These main changes include: the replacement of the kerosene fuel by LH2, the location of LH2 fuel tanks, the removal of passengers and the relocation of the payload.

\subsection{Symmetric loading cases}

Symmetric loading cases are those developed by the airplane in flight in response to the application of the pitch motivator or induced by gusts. Flight envelopes ( $\mathrm{n}-\mathrm{V}$ diagrams) were 
developed for both MTOW and OEW cases. Critical corner points of the $\mathrm{n}-\mathrm{V}$ envelope where analyzed under steady state and unchecked control inputs. Tail forces and inertial relief due to airplane acceleration were estimated according to [22].

\subsection{Landing loading cases}

During landing, the airplane's kinetic energy is suddenly absorbed by the undercarriage generating large point loads on the fuselage. For the present analysis two and three-point level landing conditions are analyzed following the calculation methodology is given by CS-25 and [22]. Landing gear loads are set in equilibrium with inertial loads and aerodynamic loads. All calculations are carried out assuming MTOW and a vertical velocity of $1.83 \mathrm{~m} / \mathrm{s}$.

Figure 5 shows the shear force and bending moment diagrams of the analyzed loading cases. From this figure it is found that the most critical loading conditions correspond to symmetric manoeuvres with the most forward C.G. location.

\subsection{Internal pressure}

Under critical conditions both LH2 tanks are subjected to the maximum uniform internal pressure of $0.172 \mathrm{MPa}(25 \mathrm{psi})$ plus the hydrostatic pressure increments created inside the tank due to the aircraft acceleration. Hydrostatic pressure increments are linearly dependent on the magnitude and direction of the aircraft acceleration and tank dimensions (length, width and height). CS-25.963 gives a simple model to estimate the hydrostatic pressure increment for large airplanes.

$$
P(L)=\rho K g L
$$

Where $\mathrm{L}$ is the maximum characteristic length in the direction of the acceleration and $\mathrm{K}$ is a linear acceleration in g's that could take any of the following values: $K=9 \mathrm{FWD}$ (inside), $\mathrm{K}=4.5$ FWD (outside), K=1.5 AFT - INBOARD - OUTBOARD, K=6 DOWN, K=3 UP 
For this case the maximum pressure increment occurs when $K=9$ and their values are $44 \mathrm{KPa}$ for the FWD tank and 43KPa for the AFT tank. Pressure increments vary linearly along the length of the tank localizing the maximum value at the most FWD end.
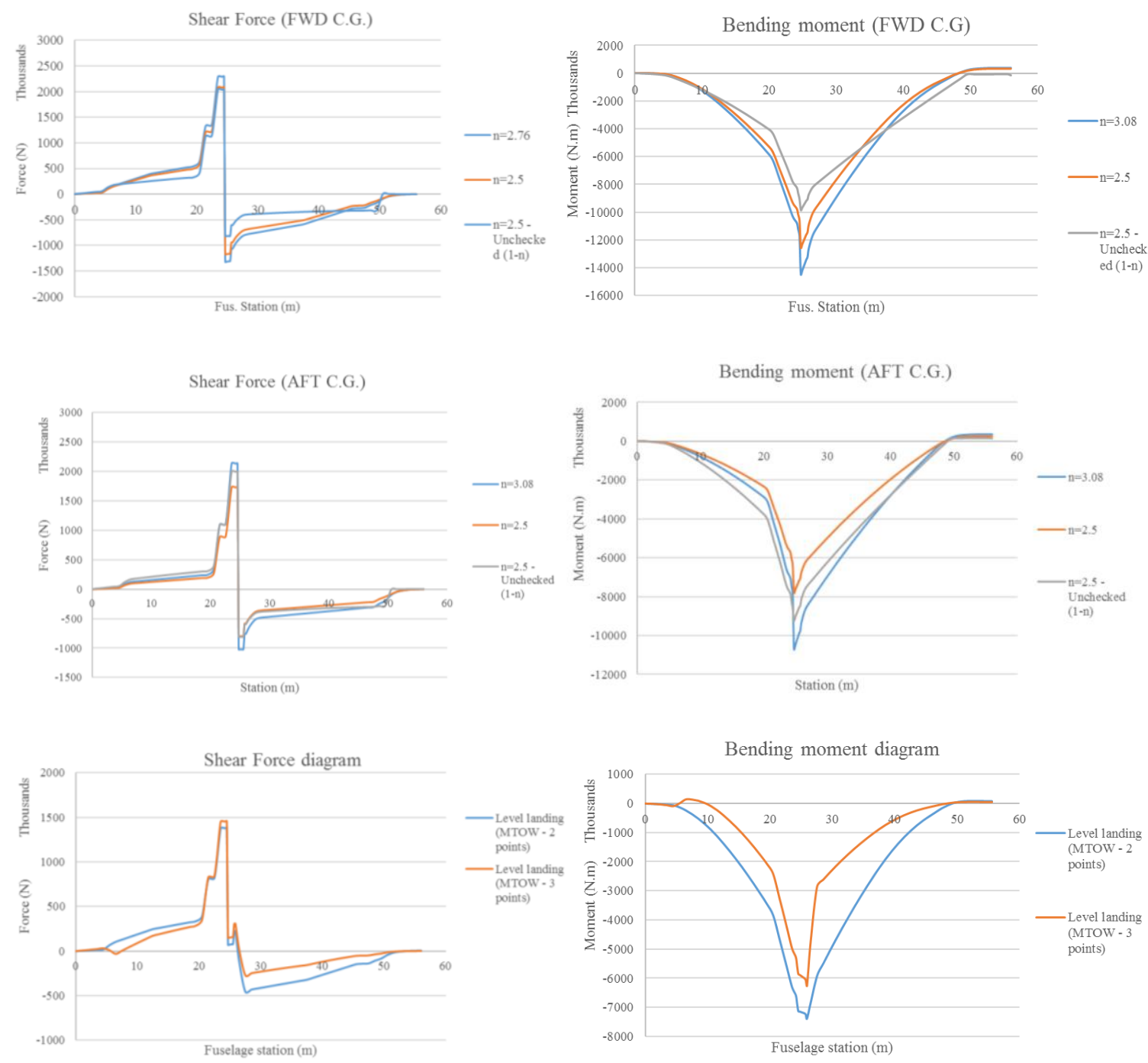

Figure 5. Shear force and bending moment diagrams (symmetric manoeuvres and

\section{landing)}

\section{FEA analysis}

Each fuel tank is independently analyzed using linear Finite Element Analysis (FEA) in order to estimate the stress distribution under the most critical loading condition (2.5g, MTOW, 1-n Unchecked). CATIA is used to preprocess the geometry while MSC. NASTRAN/PATRAN is employed for solving the FEA model. 


\subsection{Meshing}

2D elements (plane stress) were used to represent the tank skin whilst stringers and frames were represented with 1D beam elements according to the structural details given in Table 2 . Stringers and frames are meshed using Bar2 elements with a global element length of $150 \mathrm{~mm}$. The skin was meshed by employing linear interpolation displacement elements such as quad4 and Tria3. Isomesh was used for most of the surfaces except for non-parametric surfaces where holes are located; in such a cases paver distribution is preferred. A mesh size of $50 \mathrm{~mm}$ was used in stress concentration regions such as holes edges. Equivalence of nodes was applied over the mesh with a tolerance of $3 \mathrm{~mm}$ in order to ensure the continuity of the structure. Figure 6 shows a detailed representation of the mesh used for each structure during the analysis.

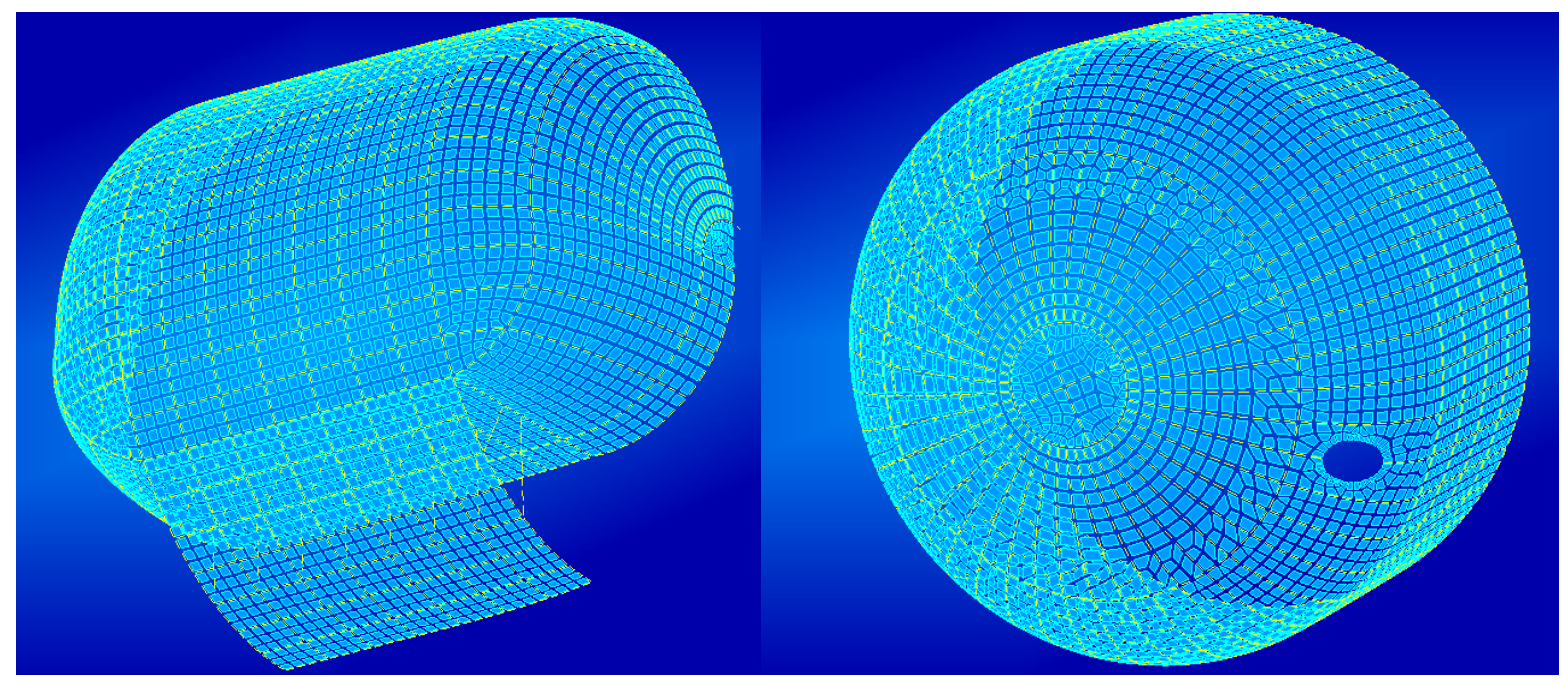

Figure 6. Meshing. a) FWD tank, b) AFT tank

\subsection{Materials}

All materials used were created as linear elastic according to the properties extracted from

Table 3. Spatial fields were applied to all materials to account for the difference in mechanical properties at cryogenic temperatures. 


\subsection{Boundary conditions}

The continuity of both fuel tanks and the fuselage was ensured by constraining the AFT heavy frame of each tank. For this component, all nodes are constrained in all DOF (displacements and rotations in $\mathrm{X}, \mathrm{Y}, \mathrm{Z}$ ). A similar boundary condition is used by [23] during the FEA analysis of LH2 tank bulkhead for the Ariane 5 rocket.

Figure 7 shows the external loading applied over each fuel tank. An internal pressure of 0.172 MPa (25 psi) was applied over all skin surfaces ensuring the direction of the pressure field points outwards. Shear forces and bending moments were applied at the non-restrained heavy frame of the tank according to the values extracted in Figure 5.

For simplicity, the bending moment was applied using a spatial field that represented axial loads acting along stringer nodes according to beam theory. Although this approach neglects the bending stiffness of the skin this assumption is conservative and widely used for preliminary stress analysis of airplane structures [24], [25]. [26] provides extensive examples for the use of this method in the modelling of airplane structures in NASTRAN/PATRAN. Thermal stresses were included through the whole structure applying a temperature load of $250.6^{\circ} \mathrm{C}$ in every node.

Hydrostatic pressure increments were applied as a linear spatial field in the longitudinal direction taking maximum pressure values of $43 \mathrm{KPa}$ and $44 \mathrm{KPa}$ for the FWD and AFT tanks respectively. External loads acting over each tank were uniformly distributed among frames 


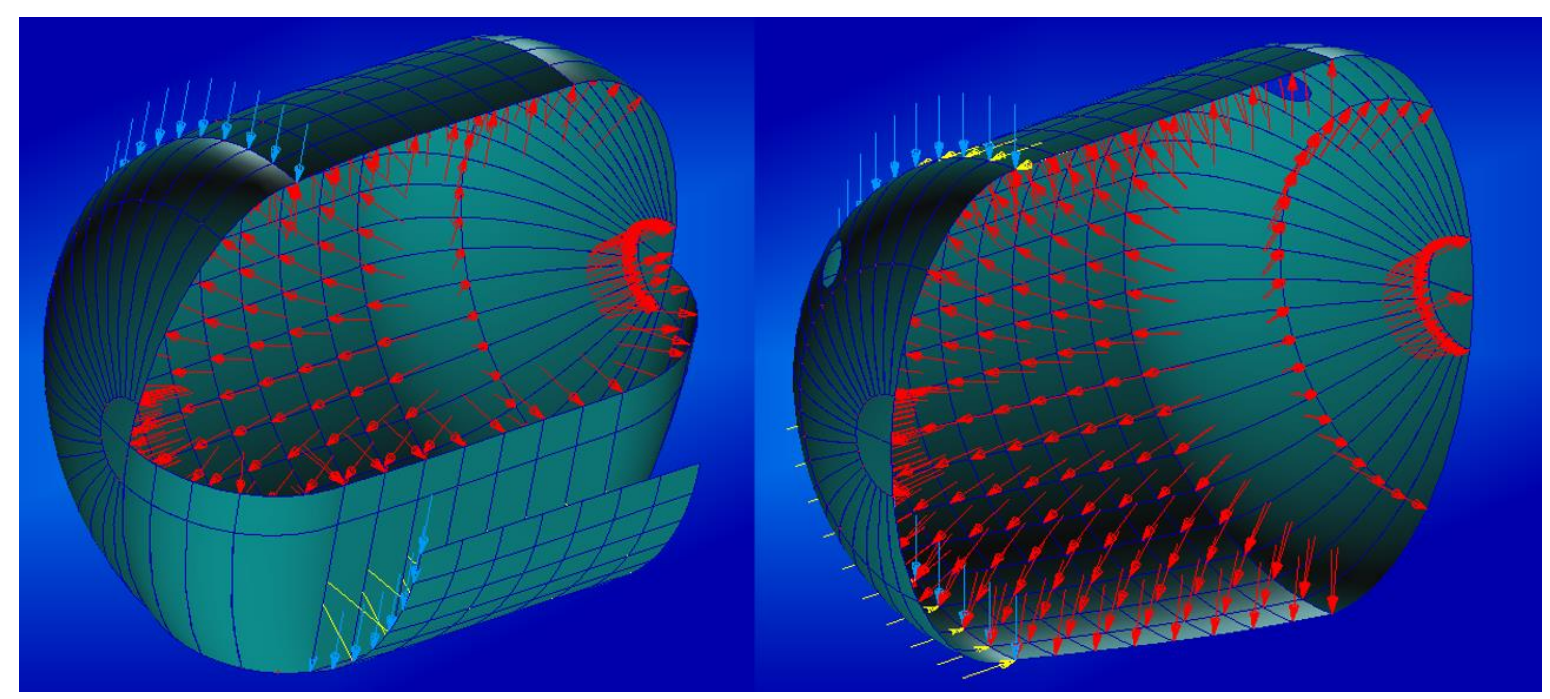

Figure 7. External loading. a) FWD tank, b) AFT tank

\subsection{Results}

Figure 8 and Figure 9 show the stress distribution of each fuel tank. Von Mises stresses are shown for both structures whilst minimum combined and maximum combined stresses are shown for FWD and AFT tanks respectively. The stress distribution is plotted using a color bar scale to show regions of high stress. Deformations are plotted in real scale.

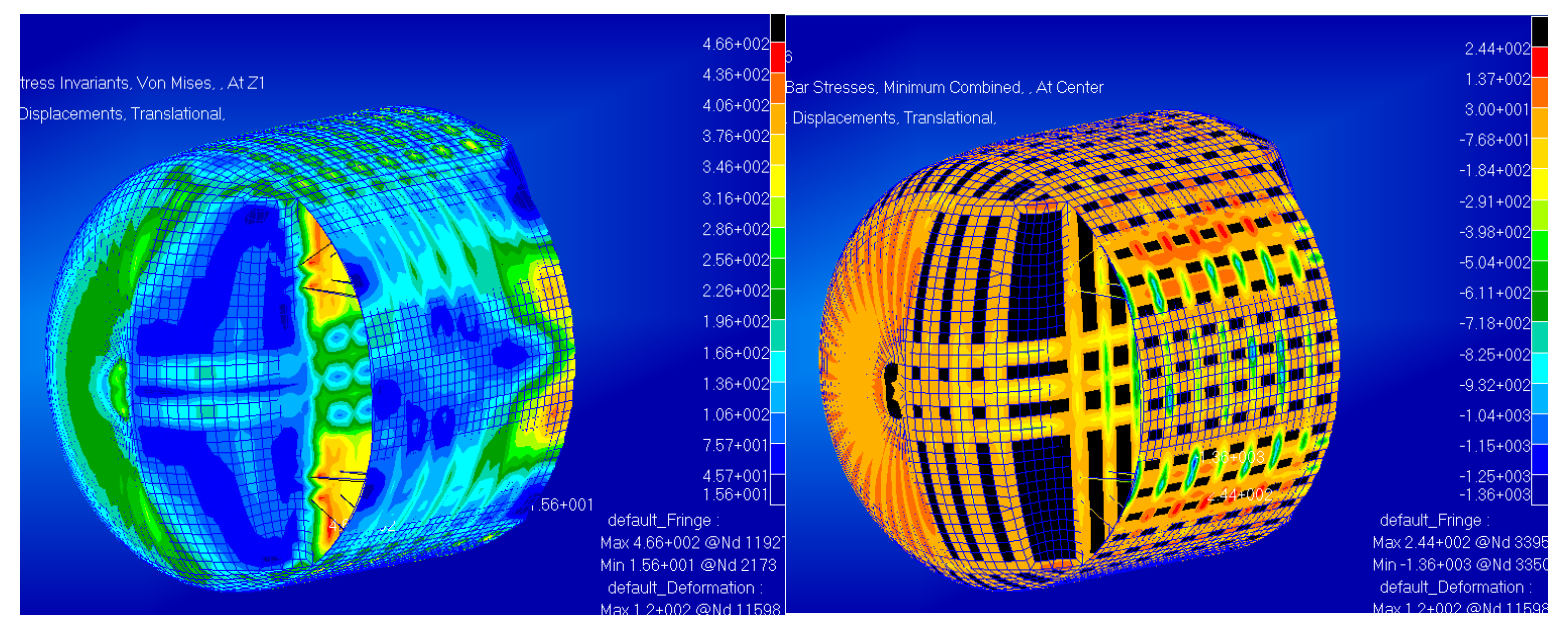

Figure 8. FWD tank stress distribution. a) Von Mises stress, b) Bar minimum combined 


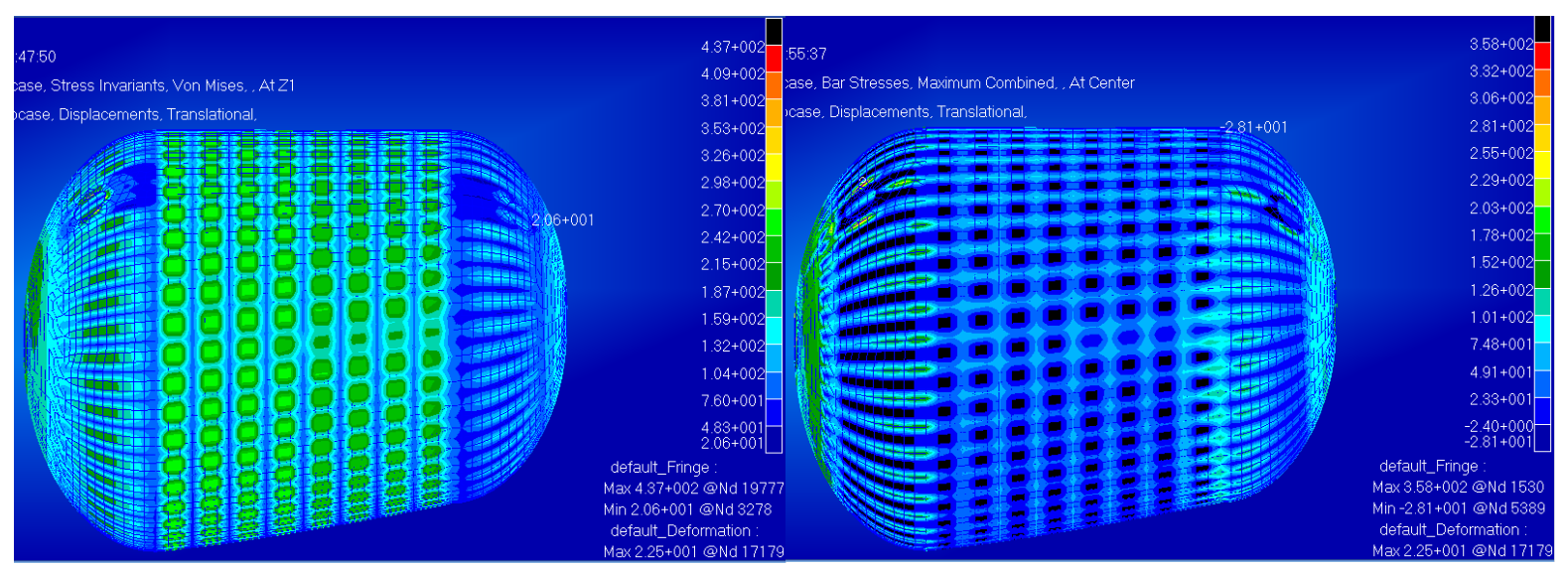

Figure 9. AFT tank Stress distribution. a) Von Misses, b) Bar maximum combined

Most of the FWD tank structure is subjected to tensile stresses in the range of 25 to $400 \mathrm{MPa}$ with exception of the catwalk dome where there is a high region of Poisson compressive stresses in the range of 20 to $213 \mathrm{MPa}$. Notable is the significant influence of the local radius of curvature on the tensile stress magnitude, this is clear when comparing the magnitude of the stress distribution on the semi-elliptical dome with respect to the catwalk semi-dome. Beam elements of the airplanes' fuselage (stringers and frames) are subjected to maximum axial stresses in the range of $-125 \mathrm{MPa}$ to $138 \mathrm{MPa}$.

Maximum principal stress of $454 \mathrm{MPa}$ is found in the root of the catwalk wall whilst the maximum bar combined stress (1720 MPa) takes place at the joint of catwalk rods and fuselage frames. The high-stress intensity in this region enforces the use of titanium. Rods used to transfer the pressure load over the catwalk wall are exposed to compressive stresses in the range of $200 \mathrm{MPa}$. For this reason a detailed buckling analysis is required during the detailed design phases.

Most of the Aft tank structure is subjected to tensile stresses in the range of $20 \mathrm{MPa}$ to 300 $\mathrm{MPa}$. The relationship between the radius of curvature and the stress level in different regions is clear. Stress distributions in the domes are characterized by two regions, delimited by the change in the local curvature of the elliptical shape. Regions close to the main axis of the ellipse 
present lower stress intensities, for this reason, it is ideal to locate openings such as holes in this area rather than in more stressed regions. In the central section, also called the "barrel section", the stress distribution over the skin varies along the longitudinal axis due to the reduction of the fuselage radius when approaching the tail. This is a predictable behaviour based on analytical models for circular pressurized vessels.

Maximum stresses and displacements are found in the access hole located in the right-hand side of the tank as well as in the openings located in both domes. Table 4 shows a summary of critical stresses and deflections found on each structure.

\begin{tabular}{lll|ll}
\hline & \multicolumn{2}{l|}{ FWD tank } & \multicolumn{2}{l}{ AFT tank } \\
\cline { 2 - 5 } & Value & M.S. & Value & M.S. \\
\hline Max. displacement(mm) & 120 & N/A & 22.5 & N/A \\
Max. stress -Von Mises (MPa) & 466 & 0.01 & 437 & 0.08 \\
Min. stress (Von Mises) (MPa) & 15.6 & 29.19 & 20 & 22.55 \\
Max. stress - Principal (MPa) & 454 & 0.04 & 397 & 0.19 \\
Min. stress - Principal (MPa) & -537 & 0.19 & -36 & 12.08 \\
Max. bar stress - Max. combined (MPa) & 1720 & 0.01 & 358 & 0.78 \\
Min. bar stress - Min. combined (MPa) & -1360 & 0.27 & -196 & 2.25 \\
\hline
\end{tabular}

Table 4. Summary of FEA results

\section{Special considerations}

\subsection{Catwalk shape}

The catwalk shape is critical in the design of the FWD LH2 fuel tank due to its significant contribution to the total tank weight since the reinforcements are required. A proper catwalk shape is such that it allows access into the passenger cabin but also distributes membrane stresses efficiently. The local radius of curvature plays a key role in the stress intensity of 
pressure vessels. It is well known that membranes are ideal to equilibrate tensile stresses however such a perfect shape is unlikely to be achieved in the FWD tank due to the catwalk. Simple linear FEA analyses are developed to evaluate the stress distribution of three catwalk shapes (flat, concave, convex-concave). The same cylindrical cross-section was used for the three configurations. The catwalk wall was located such a way that its location along the horizontal axis coincides with $30 \%$ of the fuselage radius. All structural components (including the catwalk wall) are made from the same material and thickness. Three frames made from $\mathrm{L}$ sections are located along the surface at a constant pitch. Two stringers made from L sections are located in the joint of fuselage barrel and the catwalk wall.

The FEA model was developed using typical 2D and 1D elements. All surfaces were simulated with plane stress elements whilst stringers and frames were modelled using beam elements. The mesh is entirely developed using quad4 elements in an iso-mesh distribution.

\begin{tabular}{ll}
\hline Geometry & \\
\hline Diameter $(\mathrm{mm})$ & 1000 \\
Frame pitch (mm) & 300 \\
wall location (\% R) & 30 \\
Skin thickness (mm) & 22 \\
Frames section & $\mathrm{L}-25 \times 25 \times 2$ \\
Stringers section & $\mathrm{L}-25 \times 25 \times 2$ \\
Material & \\
E $($ Mpa $)$ & 79000 \\
N & 0.3 \\
FEA & \\
Mesh size (mm) & 50
\end{tabular}




$$
\text { Pressure (MPa) } \quad 0.172
$$

\section{Table 5. FEA parameters - catwalk}

Two boundary conditions were applied for each simulation, an internal pressure of $0.172 \mathrm{MPa}$ (25psi) over the internal surfaces and a nodal displacement restraint in $\mathrm{X}, \mathrm{Y}$ and $\mathrm{Z}$ over one of the edges. Figure 10, Figure 11, and Figure 12 show the stress distribution over each catwalk concept.

a. Flat vertical catwalk: The flat catwalk is stiffened with a central stiffener and 6 rods located in the upper and bottom parts in order to distribute some membrane reactions of the catwalk wall into the unpressurized structure. Figure $\mathbf{1 0}$ clearly shows that the stress distribution over the flat surface of the catwalk is considerably reduced. However, compressive stresses in the connecting rods are large requiring thick and short rods. It is important to notice that over much of the wall location the stress distribution seems to be independent of the wall reinforcement. Its value is in the range of 0 to 50 $\mathrm{MPa}$.

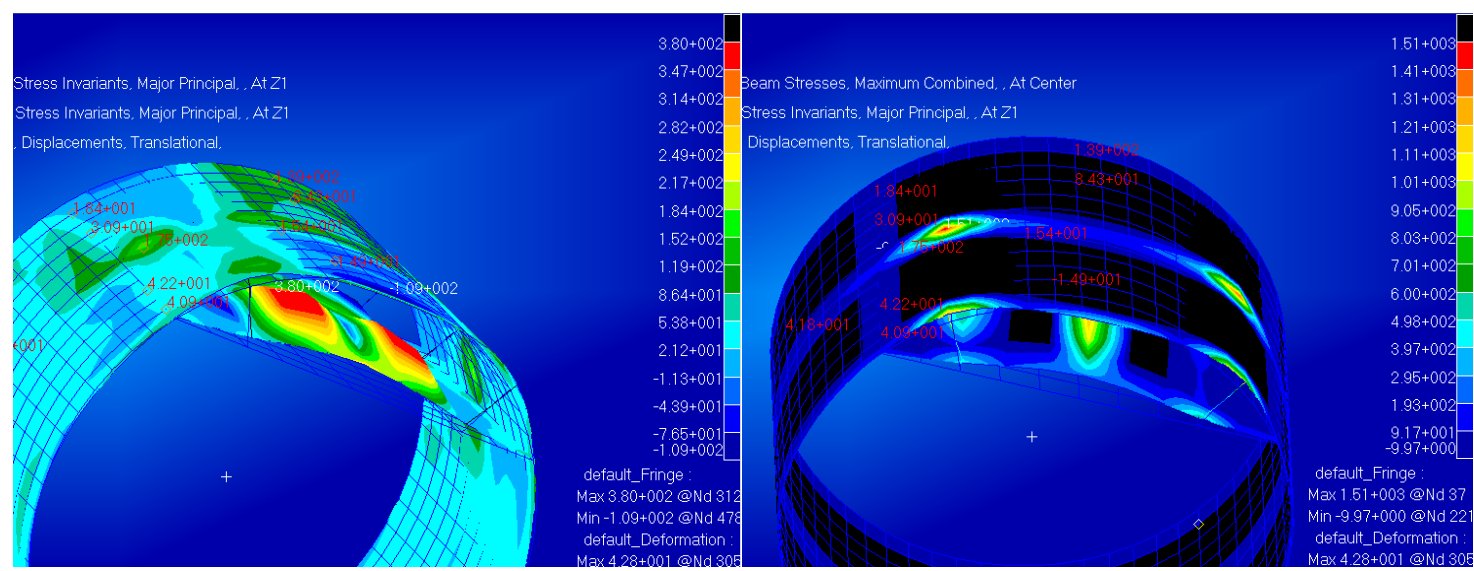

Figure 10. Stress distribution Flat catwalk. a) Von Misses, b) Bar maximum combined

b. Concave catwalk: From Figure 11 It is easy to notice the low stress intensity in a concave curved wall. If compared with the reinforced flat wall the major principal stress reduction is close to $53 \%$. The stress distribution over much of the wall seems to be in the range of 0 to $50 \mathrm{MPa}$, the same range of any of the flat wall configurations. 


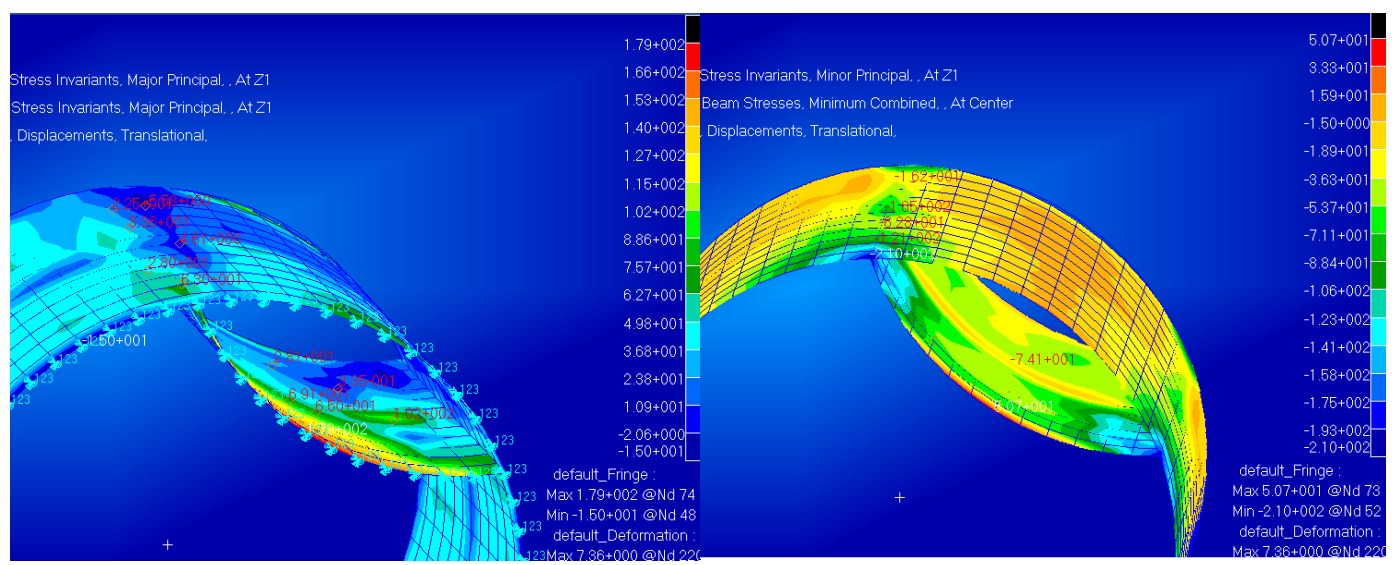

\section{Figure 11. Concave catwalk stress distribution. a) Von Misses, b) Minimum combined}

Due its concave shape the wall it is subjected to significant compressive stresses in the range of 35 to $50 \mathrm{MPa}$ that could cause instability buckling, the most critical being snap through buckling. It is also noticed from the results that the maximum stresses occur in the location where the curvature changes from convex to concave.

c. Convex-concave catwalk: A convex-concave wall is an ideal shape for avoiding high stresses in regions where the local curvature changes rapidly. Its characteristic shape provides a smooth transition for the change in curvatures and additionally provides the possibility of achieving the highest possible storage volume.

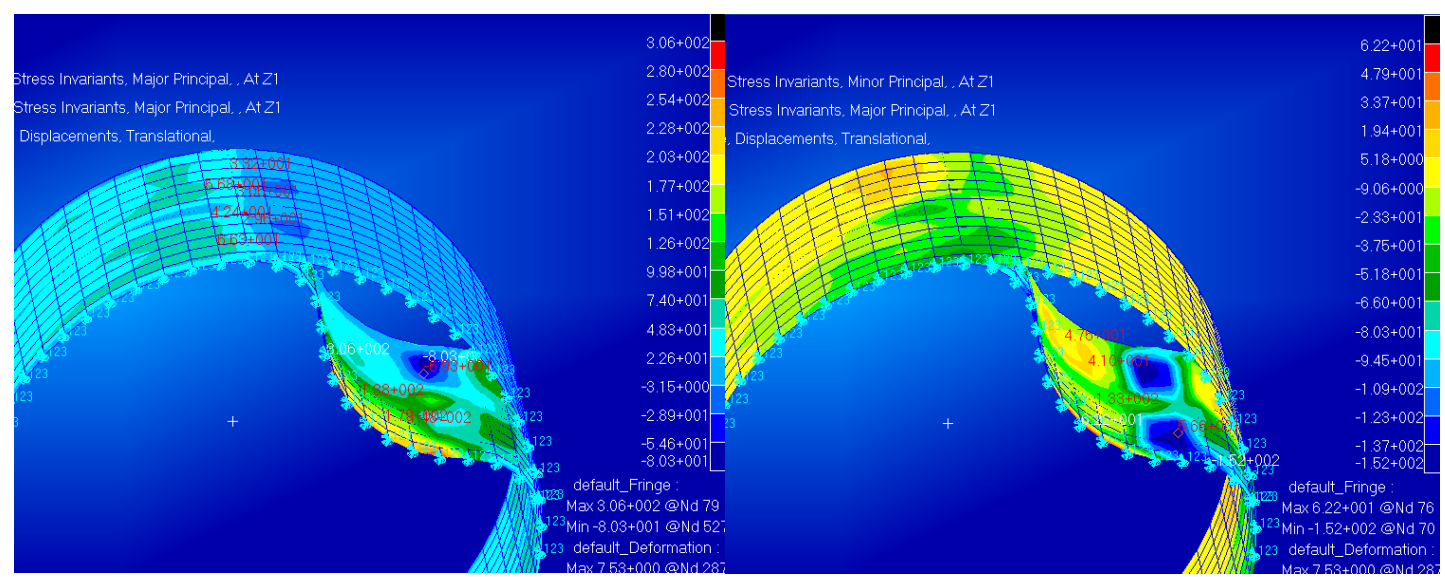

Figure 12. Convex-concave catwalk stress distribution. a) Von Misses, b) Minimum

\section{combined}

According to Figure 12 for this configuration, the maximum tensile principal stress is bigger than the concave wall. However, the minimum compressive principal stress is smaller than 
in the concave wall. It can also notice that as in all the previous wall shapes the stresses over much of the wall location are in the range of 20 to $50 \mathrm{MPa}$. Although a convex-concave wall does not present significant advantages in the tensile stress distribution its main advantage is in reducing the compressive stresses and additionally providing better volumetric efficiency than flat and concave walls. Due to its complex double curvature shape, its use in commercial aviation is restricted by manufacturing constraints implied by such a complex frame.

\section{Conclusions}

Implementing two integral LH2 fuel tanks forward and aft in the fuselage of a conventional civil airliner significantly reduces the available space for the payload. FEA analysis shows that a typical fuselage semi-monocoque structure together with pressure bulkheads (domes) is a good alternative to resist the high tank internal pressure. The FWD tank requires a catwalk that allows the free movement of the crew to the passenger cabin. The geometrical shape of the catwalk creates a significant challenge from the structural perspective due to the high-stress intensity in this region.

The results obtained in this work suggest that the weight fraction $\mathrm{W}_{\mathrm{T}} / \mathrm{W}_{\mathrm{F}}$ is at least 0.21 for AFT tanks where catwalk is not required. However, in the case of the FWD tank with a vertical flat catwalk reinforced with diagonal rods, this value can reach up to 0.35 . Additionally, it is found that heat transfer along FWD tank is $10.5 \%$ higher than in AFT tank due to the presence of the catwalk.

Concave and convex-concave catwalks are also analyzed to determine their suitability for being implemented into the FWD tank. It is found that concave catwalks produce lower stress levels in the catwalk wall than the reinforced vertical flat catwalk, however, the stress distribution is predominantly compressive encouraging structural instability. Additionally, high-stress 
concentrations are found in the regions of abrupt curvature change especially in the area where the catwalk wall joins the fuselage skin.

The convex-concave configuration provides advantages such as volumetric efficiency, small local curvatures, and smooth geometrical transition. The smooth curvature transition reduces compressive stress concentrations in the boundaries of the wall and also reduces the effective column length in the concave region decreasing the effect of structural instability. The convexconcave catwalk is very promising for future applications, however, more research in its structural instability behaviour is required.

FEA analysis shows that access holes are in regions where large deformations take place, these being a significant source of leakage that requires further reinforcement.

\section{Acknowledgements}

The authors are grateful to the Centre of Aeronautics at Cranfield University for support of this research.

\section{References}


[1] Intergovernmental panel on climate change, "Aviation and the global atmosphere," Intergovernmental panel on climate change, 1999.

[2] Airbus, "Global market forecast, mapping demand 2016-2035," 2016.

[3] OPEC, "Oil Supply and Demand Outlook to 2040," Organization of the petroleum exporting countries, 2015.

[4] OPEC, "OPEC share of world crude oil reserves," Organization of Petroleum Exporting Countries, 2015.

[5] International energy agency, "ENERGY SUPPLY SECURITY 2014," International energy agency, 2014.

[6] D. Verstraete, The potential of liquid hydrogen for long range aircraft propulsion, Cranfield, United Kingdom: Cranfield University, 2009.

[7] W. H. Wentz, R. Y. Myose and A. S. Mohamed, "Hydrogen Fueled general aviation airplanes," in AIAA 5th Aviation technology, integration and operations conference, Arlington, Virginia, 2005.

[8] G. D. Brewer, "Hydrogen Aircraft technology," CRC press, Boca Raton, United States, 1991.

[9] S. Suresh, Fatigue of materials, Cammbridge, UK: Cambridge University Press, 1998.

[10] Airbus Deutschland GmbH, "Liquid Hydrogen Fuelled Aircraft - System Analysis," European Union, 2003.

[11] A. Gomez, "ANALYSIS OF STRUCTURAL CONCEPTS OF LIQUID HYDROGEN FUEL TANKS FOR COMMERCIAL AVIATION," Cranfield University, Cranfield, United Kingdom, 2016.

[12] D. C. Maniaci, "Relative performance of a liquid hydrogen fueled commercial transport," in 46th AIAA Aerospace sciences meeting and exhibit, Reno, Nevada, 2008.

[13] Taming liquid hydrogen: The centaur upper stage rocket 1958-2002, Washington D.C.: National Aeronauticas and Space Administration (NASA), 2004.

[14] G. L. Mills, B. B. and A. O. , "Design, fabrication and testing of a liquid hydrogen fuel tank for a long duration aircraft," Advances in Cryogenic Engineering, pp. 773-773, 2012.

[15] European Aviation Safety Agency, Certification specifications and acceptable means of compliance for Large Aeroplanes CS-25, 2016.

[16] American National Standards Institute (ANSI), ANSI/AIAA S-080- 1998 Space Systems - Metallic Pressure Vessels, pressurized structures, and pressure components, Reston, Virginia: American Institute of Aeronautics and Astronautics (AIAA), 1998.

[17] L. G. G. C. a. B. C. B. Walters, "Novel Senior Design Approach of a Hydrogen Citation X," in 48th AIAA Aerospace Sciences Meeting Including the New Horizons Forum and Aerospace Exposition, Orlando, Florida, United States, 2010.

[18] Wolfgang P.P. Fischer, Antje Laabs, Ugis Cabuli, Ugis Cabulis and Vladimir Yakushin, "Internal Cryogenic Insulation for LH2 Tanks of Future Launchers," in 46th International Conference on Environmental Systems, Vienna, Austria, 2016.

[19] C.S. Lin, N. T. Van Dresar and M. M. Hassan, "A pressure control analysis of cryogenic storage systems," in 27th Joint Propulsion Conference, Sacramento, Calfornia, 1991.

[20] D. Verstraete, P. Hendrick, P. Pilidis and K. Ramsden, "Hydrogen fuel tank for subsonic transport aircraft," International journal of hydrogen energy, pp. 11085-11098, 2010.

[21] D. Verstraete, S. Sharifzadeh and P. Hendrick, "Cryogenic hydrogen fuel tanks for large hypersonic cruise vehicles," International journal of hydrogen energy, pp. 12798-12810, 2015.

[22] D. Howe, Aircraft Loading and Structural Layout, AIAA, 2004.

[23] W. Becker and T. Wacker, "Comparison between test and analysis of a tank bulkhead loaded in the plastic range," Journal of Aerospace Science and Technology, vol. 1, pp. 77-81, 1997.

[24] T. H. Megson, Aircraft structures for engineering students, Oxford, UK: Elsevier, 2007.

[25] E. F. Bruhn, Analysis and design of vehicle structures, Jacobs publishing, 1973.

[26] M. Greenberg, "Surface moments and total load at a point in MSC/PATRAN," Fracture proof research, 2011.

[27] Department of Defense of the United States of America, MIL-HDBK-5H Metalic materials and elements for aerospace vehicle structures, 1998. 
2019-09-30

Liquid hydrogen fuel tanks for commercial aviation: structural sizing and stress analysis

\author{
Gomeza, Arturo
}

Elsevier

Gomez A, Smith H. (2019) Liquid hydrogen fuel tanks for commercial aviation: structural sizing and stress analysis. Aerospace Science and Technology, Volume 95, December 2019, Article number 105438

https://doi.org/10.1016/j.ast.2019.105438

Downloaded from Cranfield Library Services E-Repository 